\title{
A Big-Data Based Customer Relationship Management Model in Customer-to-Business E-Business
}

\author{
Chen Tingbin ${ }^{1, a^{*}}$ and Jiacong Zhao ${ }^{2, b}$ \\ ${ }^{1}$ Dalian Neusoft University of Information, Dalian, China \\ ${ }^{2}$ Dalian Neusoft University of Information, Dalian, China \\ achentingbin@neusoft.edu.cn, ${ }^{\mathrm{b}}$ zhaojiacong@neusoft.edu.cn \\ * The Corresponding Author
}

\begin{abstract}
Keywords: Customer-to-business; Customer relationship management; Big-data; Case based reasoning; Likelihood ratio
\end{abstract}

\begin{abstract}
Recent companies should pay significant attention to customer requirements so as to rapidly respond to market needs and changes. $\mathrm{C} 2 \mathrm{~B}$ is the reverse model of the traditional Business-to-Customer e-commerce strategy which enables consumers to name products or services such that the organization can generate the demand collection for a specific good or service. Customer relationship management (CRM) combines people, processes and technology to understand customer requirements. This project proposes a big-data based customer relationship management (CRM) model in customer-to-business (C2B) e-commerce. This conceptual big-data based CRM model types the big-data based information technology strategy perspectives to the CRM perspectives in $\mathrm{C} 2 \mathrm{~B}$ e-commerce for scale, scope, speed and agile e-business. Additionally, case based reasoning (CBR) is introduced in this model for logic predicate and propositional logic, which contributes to the likelihood and preferences calculation of new proposed products or services. Percentage calculation, Chi-square testing and correlation calculation algorithms are introduced for performance evaluation of this model.
\end{abstract}

\section{Introduction}

Nowadays, as the highly development of computer technology and the popularization of social networks and communication tools exposes customers to extensive products and market information. In this situation, users' dynamically changing requirements and expectations incurs the fast growing of service-oriented thinking paradigms in e-business filed. This incurs the proposition of a demanding business model which is named as Customer-to-Business (C2B). C2B is the reverse model of the traditional Business-to-Customer e-commerce strategy. It enables consumers to name products or services such that the organization can generate the demand collection for a specific good or service. With this model, companies can synthesis individual's preferences into a group's consensus so as to gain competitive advantage timely and achieve sustainable business development process productively. Information technology is one of the most dramatic drivers for progressing organizational performance by radically redesigning business processes. Customer relationship management (CRM) combines people, processes and technology to understand customer requirements. CRM is premised on the belief that one of the best way to win loyal customer who is relatively profitable than non-loyal customer is to develop a trustworthy relationship with customers [1]. Additionally, Frederick Reichheld has stated that, CRM is customer oriented which enables a company to achieve significant increases in profits from improving customer satisfaction and retention rates $[2,3]$. What's more, recent companies should rapidly respond to market needs and changes, which notice large proportion of them that the data they own and how they use it can distinguish them from competitors. Big-data technology updates traditional business model with powerful data mining and text mining techniques. This makes companies more collaborative, virtual, accurate, synchronous, adaptive and agile. This project contributes a conceptual Big-Data based CRM (BD-CRM) framework in $\mathrm{C} 2 \mathrm{~B}$ e-commerce by typing the Big-data based information technology strategy perspectives to the CRM perspectives in $\mathrm{C} 2 \mathrm{~B}$ e-commerce for scale, scope, speed and agile e-business. After briefly 
reviewing the impact of BD-CRM, percentage calculation, Chi-square testing and correlation calculation algorithms are used for evaluating the performance of this model.

The rest of this paper is arranged as followings. Section 2 briefly describes the related work and theoretical background of this project. Then, specifying the framework design of BD-CRM in section 3. Section 4 evaluates BD-CRM with formal methodologies and explaining data analysis and related findings. Conclusion is given in Section 5.

\section{Related Work}

In the mid-1990s, CRM is emerged in the information technology field for describing technology based customer solutions. Fickel defined the enterprise resources management system based CRM applications as linking front office and back office with touch points [4]. Front office means the technologies that a company uses to support those departments that involve directly with consumers like sales, marketing and customer service. Back office refers to applications that support organizations' internal administrations and supplier relationships, such as financial processes, operations, logistics and human resources. Touch points include the Internet, e-mail, direct mail, telemarketing operations, call centers, advertising, fax, papers, stores and kiosks. Additionally, Adrian and Pennie figure out CRM perspectives in e-business model through strategic aspects [10], which can be widely adopted by $\mathrm{C} 2 \mathrm{~B}$ e-commerce. What's more, Injazz and Karen classifies key perspectives of CRM comprehensively through customers, functions, enterprise and technology aspects. Some recent researches are combing big-data technology with business model for gaining competitive advantages. For instance, a big-data based customer behavior analysis for decision making process in $\mathrm{B} 2 \mathrm{C}$ E-commerce is proposed [6]. Big-data technology is used in B2C model for market information analysis so as to win higher customer loyalty rate [7].

The cloud based environment provides auto scaling to handle unpredictable demand spikes, speeds up systems, reduces infrastructure cost and improves site availability. This significantly supports data mining techniques in business field. For example, big data warehouses like Hadoop [8], are recently widely used in business areas for semi-structured and un-structured data storage. Hadoop maintains metadata for files and requests on files. Besides, metaMaker which is an automatic metadata generation tool based on XML is introduced in B2C e-commerce for obtaining customer preferences automatically [6]. Additionally, Neural Networks \& Artificial Intelligence tools which are mainly focused on mathematical concepts, such as Case based reasoning (CBR), are mutual enough to support logic predicate and propositional logic in e-business. Furthermore, percentage calculation, Chi-square testing and correlation calculation algorithms are widely used in business performance evaluation. A formal strategic assessment methodology for CRM in e-business proposed in [9]. An intuitionistic fuzzy network based assessment work for the performance of C2B model is proposed in [10].

\section{Model Design}

C2B e-commerce integrates collaborative information of customers into the products and services provided by the company. In this situation, on one hand, the proposed model focuses on, analyzing the related collaborative information produced by customers so as to predict products and services which are preferred by these customers. On the other hand, new ideas proposed by C2B companies can be matched with the analyzed collaborative information through the CRB system, which enables the performance evaluation of these new cases. This model is depicted in the Figure. 1. As shown in Figure.1, at the first stage, this model classifies the collaborative information of CRM into the following three categories. Firstly, the customer profile which contains potential customer profiles, customer segments profiles and information about individual customer. This is for better responsiveness to customer needs and increased customer satisfaction. Secondly, products files contain information about customer requirements and description about products and services, such as product ranges, compatibility between computer hardware components, or the efficacy of specific 
body builder sport facilities. The third part is the market files which depict market related information like cross-selling, target marketing comparison and market research.

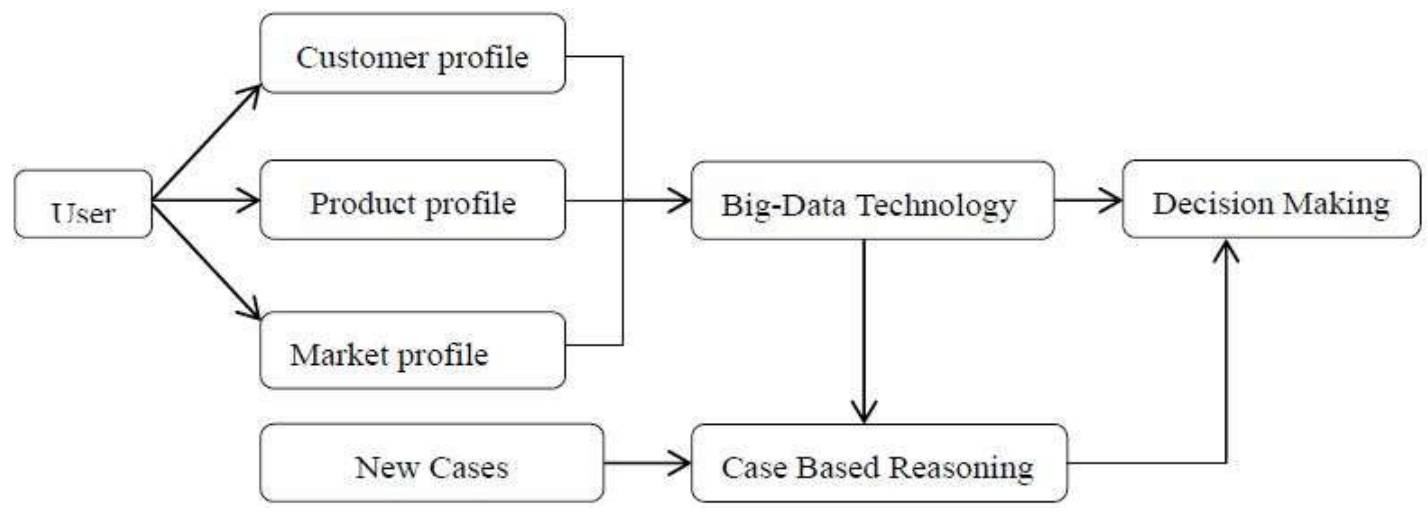

Figure 1. BD-CRM Model

The second phase in moving through this model is to acquire data. The big-data technology part applies a series of big-data related tools to obtain worthwhile knowledge to support the decision making of $\mathrm{C} 2 \mathrm{~B}$ companies. These tools and functions are shown in Table.1.

Table 1 Big-data Tools

\begin{tabular}{|c|c|}
\hline Tools & Function \\
\hline Hadoop & Data Storage \\
\hline MetaMaker & Data Extraction \\
\hline Case Based Reasoning & New Cases Testing \\
\hline
\end{tabular}

Specifically, in order to ensure reliability and data availability, the data warehouse of this project adopts the Hadoop database. Hadoop is a distributed file system which consists of NameNodes and DataNodes services. NameNodes are responsible for maintaining the metadata for files, while DataNodes store and service requests on files as directed by the NameNodes. In addition, information are processed by Natural Language Processing [12] which retrieves unlocked XML data and then applies data mining and text mining to calculate customer preferences automatically. Information from customers is often in text form, excluding data mining, text mining techniques is significantly in this project. Automatic data generation tool metaMaker is introduced in this project for data extraction. MataMaker is based on XML and uses both dependent and independent data sets for processing of the inputs and then deliver the result in diverse business levels, such as multiple functions, color spectrums, price ranges and parameters like shape, size and weight. After pervious mentioned techniques, this part outputs the prediction of customer preferences and requirements for supporting the decision making. The outcome can also be regarded as the input of the CBR component to support the new cases testing phase. Inputting big-data outcome to CBR and adding the information of the new proposed cases, CBR system can predict the likelihood of this new proposed product or service being purchased by customers. This CRB outcome is also used to support the decision making. The internal working mechanism of this part is shown in Figure.2.

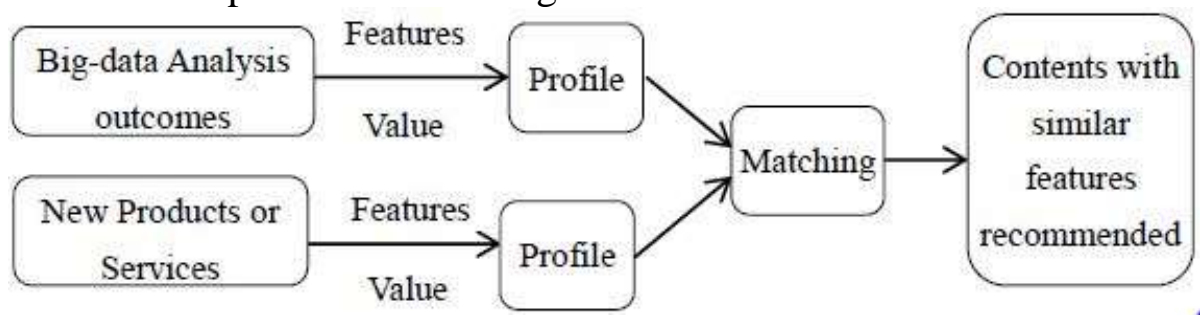

Figure 2. Working Mechanism of New Cases Testing 


\section{Model Evaluation}

The evaluation data of this project is collected from the social networks and official website of a C2B toggery manufacture located in a city named Dalian. The analyzed outcome of this model shows that, compared with male, female account for larger population in respondents. The age group falls mainly at 20 to 45 . It is inferred that the average income of each mouth is above $6000 \mathrm{RMB}$. Model performance is assessed using evaluation tools like percentage analysis, chi-square test, and correlations. The analyzed data shows that product quality is one of the most significant requirements from customers, and the relationship between quality and consumer age groups is shown in Table.2. The product quality is compared based on current available goods in the stores. This result suggests manufacture that excluding the age below 20, product quality to the rest three groups should be paid highly attention.

Table 2 Relationship between product quality and age groups

\begin{tabular}{|c|c|c|c|c|}
\hline \multirow{2}{*}{ Age groups } & \multicolumn{3}{|c|}{ Product Quality } & \multirow{2}{*}{ Total } \\
\cline { 2 - 4 } & Very Important & Important & Not Important & \\
\hline Below 20 & 15 & 32 & 25 & 72 \\
\hline $20-35$ & 32 & 69 & 67 & 168 \\
\hline $35-45$ & 22 & 56 & 36 & 114 \\
\hline Above 45 & 25 & 69 & 52 & 146 \\
\hline Total & 94 & 226 & 180 & 500 \\
\hline
\end{tabular}

The chi-square test results are shown in Table.3. The calculated result is 0.625 which is greater than 0.05. This means the hypothesis of this model in terms of preferences ratio calculation is accepted.

Table 3 Chi-square test results

\begin{tabular}{|c|c|c|c|}
\hline Particulars & Value & Freedom Degree & Significance \\
\hline Pearson Chi-Square & 7.118 & 9 & 0.625 \\
\hline Likelihood Ratio & 7.157 & 9 & 0.621 \\
\hline Linear-by-Linear Association & 0.857 & 1 & 0.355 \\
\hline Number of Valid Cases & 500 & & \\
\hline
\end{tabular}

Tabel.4 describes the correlations between the predicted market information and the location information provided current stores. The calculated person correlation coefficient value $\mathrm{R}$ is 0.133 , which means the numbers are correlated. The outcomes also indicate the relationship between gender and the location provided by this toggery manufacture. Analytical results indicate that the nature of clothes bought by different age segments of customers varies accordingly. Previous analysis shows that the performance of BD-CRM is accepted. 
Table.4 Correlation between Respondents and Location

\begin{tabular}{|c|c|c|c|}
\hline Variables & Particulars & Gender & Location \\
\hline \multirow{4}{*}{ Gender } & Person Correlation & 1 & 0.066 \\
\cline { 2 - 4 } & Significance & & 0.133 \\
\cline { 2 - 4 } & Respondents No. & & 500 \\
\hline \multirow{3}{*}{ Location } & Person Correlation & -0.066 & 1 \\
\cline { 2 - 4 } & Significance & 0.133 & \\
\cline { 2 - 4 } & Respondents No. & 500 & \\
\hline
\end{tabular}

\section{Conclusion}

This project proposes a big-data based CRM model in C2B e-commerce for company performance improvement. This model firstly conducts the big-data analysis of customer profile, product profile and market profile so as to achieve customer requirements and preferences. Regarding this analysis, recommendations are made to $\mathrm{C} 2 \mathrm{~B}$ companies based on feature values. At the same time, the big-data analysis also supports the likelihood ratio testing of new products or services. This model provides $\mathrm{C} 2 \mathrm{~B}$ companies with a better environment to understand customers and progress their business. The future work of this project is to handle big-data theories more effectively and productively and then evaluates this model performance more precisely.

\section{References}

[1] F. Reichheld with T. Teal, The Loyalty Effect (Boston, MA: Harvard Business School Press, 1996); the Peppers and Rogers web site is <www.1to1.com.>; a summary of the PWC approach can be found in S. A. Brown, Customer Relationship Management(Toronto: John Wiley \& Sons, 2000

[2] Reichheld, F.F. (1996a), The Loyalty Effect, Harvard Business School Press, Boston, MA.

[3] Jackson, D. Jr (1994), "Relationship selling: the personalization of relationship marketing", Asia-Australia Marketing Journal, August, pp. 45-54.

[4] Fickel, L. (1999), “Know your customer”, CIO Magazine, Vol. 12 No. 21, pp. 62-72.

[5] Peppers, D. and Rogers, M. (1999), The One to One Manager: Real-World Lessons in Customer Relationship Management, Doubleday, New York, NY.

[6] K.Kannan, K.Raja (2016), decision making process for B2C model using behavior analysis with big data technologies, Indian Journal of Science and Technology, vol 9(24), India

[7] Grahame Dowling, "customer relationship management: in B2C markets, often less is more", The regents of the university of California, volume 44, Number 3, Spring 2002

[8] Chandrasekar, S., et al. "A novel indexing scheme for efficient handling of small files in Hadoop distributed file system." Computer Communication and Informatics (ICCCI), 2013 International Conference on. IEEE, 2013.

[9] Adrian Payne \& Pennie Frow (2005), a strategic framework for customer relationship management, Journal of Marketing,Vol. 69 (October),167-176, American,

[10]C.Thirumalai, Senthikumar M (2016), an assessment framework of intuitionistic fuzzy network for $\mathrm{C} 2 \mathrm{~B}$ decision making,

[11]Chen, Deng-Neng, et al. "An agent-based model for consumer-to-business electronic commerce." Expert Systems with Applications 34.1 (2008): 469-481.

[12] Injazz J.Chen, Karen Popovich, Understanding customer relationship management (CRM)-people, process and technology, Business Process Management, Vol.9 No.5, 2003 
[13]Zhang S, Gu M. Applying data mining to automatically acquire user preferences in commercial web sites. IEEE International Conference on Information Engineering and Computer Science, Wuhan, ICIES09; 2009.p.1-4

[14] Peng L. Individual Choice and Reputation Distribution of Cooperative Behaviors among Heterogeneous Groups. Chaos, Solitons \& Fractals, 2015, 77: 39-46.

[15]Thirumalai, Chandrasegar, and M. Senthilkumar. "An Assessment Framework of Intuitionistic Fuzzy Network for C2B Decision Making." A A 10 (2016): 1 